\title{
En Bloc Spondylectomy for Spinal Metastases: Detailed Oncological Outcomes at a Minimum of 2 Years after Surgery
}

\author{
Masayuki Ohashi ${ }^{1}$, Toru Hirano ${ }^{1}$, Kei Watanabe ${ }^{1}$, Kazuhiro Hasegawa ${ }^{2}$, Takui Ito ${ }^{3}$, Keiichi Katsumi ${ }^{4}$, \\ Hirokazu Shoji ${ }^{1}$, Tatsuki Mizouchi ${ }^{1}$, Ikuko Takahashi ${ }^{1}$, Takao Homma ${ }^{2}$, Naoto Endo ${ }^{1}$ \\ ${ }^{I}$ Department of Orthopedic Surgery, Niigata University Medical and Dental Hospital, Niigata, Japan \\ ${ }^{2}$ Niigata Spine Surgery Center, Niigata, Japan \\ ${ }^{3}$ Department of Orthopedic Surgery, Niigata City General Hospital, Niigata, Japan \\ ${ }^{4}$ Department of Orthopedic Surgery, Uonuma Kikan Hospital, Niigata, Japan
}

Study Design: Retrospective case series.

Purpose: To investigate the oncological outcomes, including distant relapse, after en bloc spondylectomy (EBS) for spinal metastases in patients with a minimum of 2-year follow-up.

Overview of Literature: Although EBS has been reported to be locally curative and extend survival in select patients with spinal metastases, detailed reports regarding the control of distant relapse after EBS are lacking.

Methods: We conducted a retrospective review of 18 consecutive patients (median age at EBS, 62 years; range, 40-77 years) who underwent EBS for spinal metastases between 1991 and 2015. The primary cancer sites included the kidney ( $n=7)$, thyroid ( $n=4)$, liver $(n=3)$, and other locations $(n=4)$. Survival rates were estimated using the Kaplan-Meier method, and groups were compared using the log-rank method.

Results: The median operative time and intraoperative blood loss were 767.5 minutes and 2,375 g, respectively. Twelve patients (66.7\%) experienced perioperative complications. Five patients $(27.8 \%)$ experienced local recurrence of the tumor at a median of 12.5 months after EBS, four of which had a positive resection margin status. Thirteen patients (72.2\%) experienced distant relapse at a median of 21 months after EBS. The estimated median survival period after distant relapse was 20 months $195 \%$ confidence interval, 0.71-39.29 months). No association was found between resection margin status and distant relapse. Overall, the 2-year, 5-year, and 10-year survival rates after EBS were $72.2 \%, 48.8 \%$, and $27.1 \%$, respectively. Importantly, the era in which EBS was performed did not impact the oncological outcomes.

Conclusions: Our results suggest that EBS by itself, even if margin-free, cannot prevent further dissemination, which occurred in $>70 \%$ of patients at a median of 21 months after EBS. These results should be considered and conveyed to patients for clinical decision-making.

Keywords: Spine; Neoplasm metastasis; Margins of excision; Recurrence; Survival

Received Jun 21, 2018; Revised Jul 23, 2018; Accepted Aug 12, 2018

Corresponding author: Masayuki Ohashi

Department of Orthopedic Surgery, Niigata University Medical and Dental Hospital, 1-757 Asahimachi Dori, Chuo-ku, Niigata city, 9518510, Japan

Tel: +81-25-227-2272, Fax: +81-25-227-0782, E-mail: masayuki-ohashi@ksh.biglobe.ne.jp 


\section{Introduction}

Spinal metastases can cause bony compromise and tumor invasion into the epidural space, progressing to axial pain and neurologic deficits. These symptoms negatively affect the quality of life (QOL) and life expectancy of patients with cancer [1-3]. Thus, the efficient control of primary and metastatic lesions is critical for prolonging survival.

En bloc spondylectomy (EBS) is a surgical procedure that enables the complete resection of vertebral malignant lesions $[4,5]$. Although metastasis generally indicates systemic cancer, EBS has been shown to be locally curative and extend survival among patients with spinal metastases [6-11]. However, most previous reports focused on local recurrence, and reports providing detailed long-term data on the control of distant metastases ('distant relapse') after EBS for spinal metastases are lacking. Because distant relapse after EBS can negatively affect QOL and lifespan, the following questions must be considered during the decision-making process: (1) What is the incidence and risk rate for distant relapse after EBS; (2) For how long can distant relapse be controlled; (3) What kind of treatment(s) will be administered; and (4) How long is the expected survival period after distant relapse? With these questions in mind, the purpose of the present study was to investigate oncological outcomes, including local and distant relapse, using a single center's 24-year experience with EBS for spinal metastases patients with a minimum of 2-year follow-up.

\section{Materials and Methods}

The ethics committee of the Niigata University Graduate School of Medical and Dental Sciences approved this study (approval no., 2017-0103). A retrospective review of all 18 consecutive patients who underwent EBS for spinal metastasis between 1991 and 2015 at Niigata University Medical and Dental Hospital, Niigata, Japan was performed. No patients were lost to follow-up. The surgical indicators for spinal metastases requiring EBS were as follows: (1) a solitary metastasis existing on the spine or a spinal metastasis with radically resectable skip lesions; (2) a tumor involving less than three consecutive vertebral levels; (3) no evidence of tumors at the primary cancer site; (4) no other metastases, or if present, metastases are stable and controllable; and (5) the patient was in good general condition (Eastern Cooperative Oncology Group performance status score $\leq 3$ ). Oncologists made all decisions about adjuvant chemotherapy and radiation therapy prior to and after EBS.

\section{Surgical technique}

In the present series, three approaches for EBS were utilized: a single posterior approach, a combined anterior and posterior approach, or a simultaneous anterior and posterior approach. EBS through the single posterior approach was performed as described by Tomita et al. $[4,6]$. However, to reduce the risk of vascular complications, EBS was more frequently performed through a combined anterior and posterior approach [5], dissecting around the tumor vertebrae via the anterior incision and following with a posterior en bloc corpectomy. Still, injury to major vessels, such as the aorta and vena cava, during en bloc corpectomy through the posterior incision was possible, and surgeons experienced difficulty in handling injured vessels, beyond the neural elements, through the posterior approach. Therefore, beginning in September 2004, EBS was performed via the simultaneous anterior and posterior approach, in one or two stages, and the surgical technique of this approach is described below.

Patients were placed in the prone position, and the posterior procedure was performed. After performing both a laminectomy at the tumor-free site and pediculotomies, dissection on the lateral aspect of the vertebrae for the non-dominant side of the tumor was performed. Posterior reconstruction involved a pedicle screw system with dual rods positioned at least two vertebral levels above and below the lesion. The simultaneous anterior and posterior procedure was either performed on the same day as the posterior procedure or 2-3 weeks after the first surgery. To begin, the patient was placed in a lateral decubitus position, with the tumor-dominant side facing upward. After a standard transpleural and/or retroperitoneal approach performed through an oblique thoracolumbar skin incision re-opened the posterior wound, a $360^{\circ}$ dissection around the tumor vertebrae was made, and discectomy or osteotomy was performed using a T-saw. Finally, the tumor vertebra was removed in an en bloc fashion through the anterior incision by pushing the tumor vertebra from the posterior side. Anterior reconstruction was performed using autologous bone, with or without a titanium cage. The posterior procedures were completed by the application of compression forces between the pedicle screw 
heads above and below the bone graft.

\section{Histological assessment and surgical classification}

All resected specimens were analyzed histologically to determine the surgical margin status $[12,13]$. The surgical margin was classified as 'positive' if a visible tumor tissue was present, the tumor was cut through during the operation, or the excision margins were positive at the microscopic level. The surgical margin was classified as 'negative' for both wide and marginal resections.

\section{Evaluations}

All patients were followed-up with radiological examinations (X-ray, computed tomography, and/or magnetic resonance imaging), which evaluated changes in the treated segments and lesions in other sites. Local recurrence was defined as recurrence in the area where EBS was performed or in an adjacent area contiguous to the EBS area. Distant relapse was defined as a new occurrence of metastasis in an area other than the EBS or surrounding areas. The distant relapse-free period was defined as the duration between EBS and the first occurrence of distant metastasis after EBS.

\section{Statistical analysis}

Statistical analyses were performed using IBM SPSS Statistics for Windows ver. 21.0 (IBM Corp., Armonk, NY, USA). Survival rates were estimated using the KaplanMeier method, and group differences were evaluated using the log-rank method. For categorical variables, group differences were evaluated using the chi-square or Fisher's exact tests. In all analyses, a $p$-value $<0.05$ was considered statistically significant.

\section{Results}

\section{Patients}

The demographics of the patients are shown in Table 1. The median age at EBS was 62 years (range, 40-77 years), and the primary cancer sites included the kidney $(n=7)$, thyroid

Table 1. Patient demographics

\begin{tabular}{ccclcccccc} 
Case & $\begin{array}{c}\text { Age } \\
\text { (yr) }\end{array}$ & Sex & Primary cancer site & Level & $\begin{array}{c}\text { Tomita } \\
\text { classification }\end{array}$ & $\begin{array}{c}\text { Metastasis to } \\
\text { vital organ }\end{array}$ & $\begin{array}{c}\text { Metastasis to } \\
\text { extraspinal bone }\end{array}$ & $\begin{array}{c}\text { Frankel } \\
\text { grade }\end{array}$ & $\begin{array}{c}\text { Tokuhashi } \\
\text { score }\end{array}$ \\
\hline 1 & 55 & F & Breast & T6 & 2 & No & No & E & 13 \\
\hline 2 & 40 & F & Thyroid & T12 & 5 & No & No & D & 14 \\
\hline 3 & 53 & M & Kidney & T10,11 & 6 & No & No & C & 9 \\
\hline 4 & 45 & F & Salivary gland & T7 & 5 & Lung & No & D & 10 \\
\hline 5 & 54 & M & Kidney & T6 & 5 & No & No & D & 12 \\
\hline 6 & 73 & M & Kidney & T10 & 6 & No & No & D & 12 \\
\hline 7 & 73 & M & Kidney & L3 & 6 & Lung & No & D & 10 \\
\hline 8 & 77 & M & Liver & T4, 8, 9, 10 & 7 & No & No & E & 9 \\
\hline 9 & 70 & M & Kidney & L1 & 6 & No & No & C & 10 \\
\hline 10 & 68 & M & Kidney & T9 & 4 & No & No & E & 11 \\
\hline 11 & 62 & M & Liver & T12 & 4 & No & No & E & 11 \\
\hline 12 & 62 & F & Thyroid & 6 & No & No & D & 14 \\
\hline 13 & 60 & M & Thyroid & L5 & 4 & No & llium & C & 11 \\
\hline 14 & 65 & F & Pulmonary epithelioid & T2, 12, L1 & 7 & No & llium, femur & D & 7 \\
\hline 15 & 65 & F & Thymama & T12 & 5 & No & No & D & 10 \\
\hline 16 & 47 & M & Liver & T12 & 1 & No & No & D & 9 \\
\hline 17 & 59 & F & Kidney & T11, 12 & 5 & No & No & E & 13 \\
\hline 18 & 62 & F & Thyroid & L2 & 5 & No & No & D & 14 \\
\hline
\end{tabular}

F, female; $M$, male. 
$(\mathrm{n}=4)$, liver $(\mathrm{n}=3)$, and other locations $(\mathrm{n}=4)$. In accordance with the surgical classifications of spinal tumors proposed by Tomita et al. [6] and on the basis of the anatomical location of the spinal tumors, one patient had type 1 (vertebral body), one patient had type 2 (pedicle extension), three patients had type 4 (spinal canal extension), six patients had type 5 (paravertebral extension), five patients had type 6 (adjacent vertebral extension), and two patients had type 7 (multiple skip lesions in the spinal column). Additionally, two patients had lung metastases, and another two had metastases in extraspinal bones. The preoperative Frankel grade was $\mathrm{C}$ for three patients, $\mathrm{D}$ for 10 patients, and $\mathrm{E}$ for five patients [14]. The median preoperative Tokuhashi score was 11 points (range, $7-14$ points) [15].

\section{Surgical procedures and clinical outcomes}

Two patients (cases 8 and 14) had skip lesions in the spinous process and laminae of the upper thoracic spine (Table 2). As a result, these patients also underwent en bloc resection for upper thoracic lesions via a posterior approach at the same time as the EBS. The median operative time and intraoperative blood loss for all patients were 767.5 minutes (range, 447-1,110 minutes) and 2,375 $\mathrm{g}$ (range, 330-18,070 g), respectively. Ten patients (55.6\%) received adjuvant therapies. Two patients received radiation therapy as adjuvant therapy: one for lung metastases (case 4) and one for iliac metastases and contaminated resected margins in the EBS area (case 13).

In 12 patients (66.7\%), 18 perioperative complications occurred. Four patients (22.2\%) underwent revision surgery for perioperative complications (surgical site infection in three patients and neurological deficits due to misplaced pedicle screws in one patient). Among the three patients with postoperative neurological deficits, neurological function was partially recovered after revi-

Table 2. Surgical procedures and results

\begin{tabular}{|c|c|c|c|c|c|c|c|c|c|}
\hline \multirow{2}{*}{ Case } & \multirow{2}{*}{$\begin{array}{l}\text { Date of } \\
\text { EBS (yr) }\end{array}$} & \multirow{2}{*}{ Approach } & \multirow{2}{*}{$\begin{array}{l}\text { Resected } \\
\text { area }^{\text {a) }}\end{array}$} & \multirow{2}{*}{$\begin{array}{l}\text { Time } \\
\text { (min) }\end{array}$} & \multirow{2}{*}{$\begin{array}{l}\text { Intraoperative } \\
\text { blood loss (g) }\end{array}$} & \multirow{2}{*}{$\begin{array}{l}\text { Adjuvant } \\
\text { therapy }\end{array}$} & \multicolumn{2}{|c|}{ Perioperative complications } & \multirow{2}{*}{$\begin{array}{l}\text { Frankel } \\
\text { grade }^{\text {b) }}\end{array}$} \\
\hline & & & & & & & Intraoperative & Postoperative & \\
\hline 1 & 1991 & C-AP & T6 & 715 & 4,300 & None & None & Pneumonia & $E$ \\
\hline 2 & 1995 & C-AP & $\mathrm{T} 12$ & 680 & 2,625 & $\mathrm{C}+\mathrm{RAl}$ & None & None & $E$ \\
\hline 3 & 2001 & C-AP & $\mathrm{Tg}, 10,11$ & 1,073 & 3,478 & None & None & Paralytic ileus & $D$ \\
\hline 4 & 2001 & P & $\mathrm{T}(6), 7,(8)$ & 1,067 & 410 & $\mathrm{R}$ & None & Pneumonia & $D$ \\
\hline 5 & 2004 & C-AP & $\mathrm{T} 6,(7)$ & 713 & 1,744 & None & None & None & $E$ \\
\hline 6 & 2004 & S-AP & T10, (11) & 1,015 & 18,070 & None & None & ND, UTI & $D$ \\
\hline 7 & 2005 & S-AP & L3 & 922 & 3,891 & C & None & None & $E$ \\
\hline 8 & 2007 & S-AP & T8, 9, 10 & 1,110 & 2,125 & C & None & ND, SSI & $E$ \\
\hline 9 & 2008 & S-AP & (T12), L1 & 834 & 8,245 & C & Durotomy & SSI & $D$ \\
\hline 10 & 2009 & S-AP & T9 & 627 & 1,670 & C & None & None & $E$ \\
\hline 11 & 2010 & S-AP & $\mathrm{T} 12$ & 755 & 1,235 & None & None & None & $E$ \\
\hline 12 & 2011 & S-AP & $L(2), 3,(4)$ & 632 & 7,512 & RAI & Durotomy & None & $E$ \\
\hline 13 & 2012 & S-AP & L5 & 881 & 3,215 & $\mathrm{R}$ & Vena cava tear & ND, DVT & $E$ \\
\hline 14 & 2013 & S-AP & $\mathrm{T} 12, \mathrm{~L} 1$ & 780 & 1,715 & None & Durotomy & None & $D$ \\
\hline 15 & 2013 & S-AP & $\mathrm{T} 12$ & 609 & 1,790 & None & Durotomy & None & $E$ \\
\hline 16 & 2014 & P & $\mathrm{T} 12$ & 447 & 1,180 & None & None & None & $E$ \\
\hline 17 & 2014 & S-AP & $\mathrm{T} 11,12$ & 783 & 330 & C & None & SSI & $E$ \\
\hline 18 & 2015 & S-AP & $L(1), 2$ & 712 & 3,245 & None & $\begin{array}{l}\text { Aorta and vena } \\
\text { cava tear }\end{array}$ & SSI & $D$ \\
\hline
\end{tabular}

EBS, en bloc spondylectomy; C-AP, combined anterior and posterior approach; C, chemotherapy or hormonal therapy; RAl, radioactive iodine therapy; P, posterior approach; R, radiation therapy; S-AP, simultaneous anterior and posterior approach; ND, neurological deficits; UTI, urinary tract infection; SSI, surgical site infection; DVT, deep venous thrombosis.

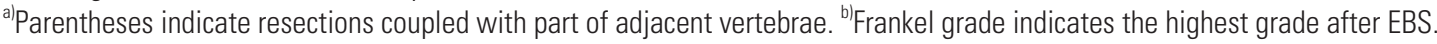


sion surgery in one patient (case 6) and fully recovered without revision in two patients (cases 8 and 13).

Five patients $(27.8 \%)$ required revision surgeries because of the mechanical failure of spinal instrumentation, including rod breakage due to pseudarthrosis $(n=4)$, and fractures in the uppermost $(n=1)$ or lowermost $(n=1)$ instrumented vertebra. All patients had improved or preserved Frankel grade after EBS. Sixteen patients (88.9\%) could walk independently after EBS, and two patients required walking aids (cane, $\mathrm{n}=1$; walker, $\mathrm{n}=1$ ).

\section{Oncological outcomes and overall survival}

In total, 10 patients had negative margins, and eight patients had positive margins (Table 3 ). Intralesional procedures were performed in eight patients: During the dissection of the tumor vertebral bodies $(n=1)$; during pediculotomy, using a fine thread wire saw (T-saw, $\mathrm{n}=1$ ); during anterior column osteotomy, using a T-saw $(n=2)$; during dissection of an epidural tumor $(\mathrm{n}=2)$; and during the removal of the tumor vertebrae, which caused other vertebral fractures $(n=2)$. Tumor remnants were completely resected piece-by-piece in patients with a macroscopic tumor tissue remaining.

Five patients (27.8\%) experienced a local recurrence. Of these, four patients had positive margins of the resected lesion, and one patient had a negative margin with a thin $(<1 \mathrm{~mm})$ tumor-free layer. The incidence of local tumor recurrence was higher for patients with positive margins (4/8 patients, 50\%) compared to those with negative margins (1/10 patients, $10 \%)$. However, this difference did not reach statistical significance $(p=0.12)$. The median duration between EBS and local recurrence was 12.5 months (range, 6-53 months), with three patients having undergone revision surgery. In two patients (cases 5 and 11) with local recurrence, the recurrent tumor around the cage caused neurological deficits and required a revision surgery (debulking) with adjuvant therapies. In one pa-

Table 3. Oncological outcomes after EBS

\begin{tabular}{|c|c|c|c|c|c|c|c|c|c|}
\hline \multirow[b]{2}{*}{ Case } & \multirow[b]{2}{*}{$\begin{array}{l}\text { Surgical } \\
\text { margin }\end{array}$} & \multicolumn{3}{|c|}{ Local recurrence } & \multicolumn{3}{|c|}{ Distant relapse after EBS } & \multirow[b]{2}{*}{ Prognosis } & \multirow[b]{2}{*}{$\begin{array}{l}\text { Follow- } \\
\text { up (mo) }\end{array}$} \\
\hline & & Yes/no & $\begin{array}{l}\text { Duration } \\
\text { after EBS } \\
\text { (mo) }\end{array}$ & Treatment & Region & $\begin{array}{l}\text { Duration } \\
\text { after EBS } \\
\text { (mo) }\end{array}$ & Treatment & & \\
\hline 1 & - & No & & & Bone & 15 & C & DOD & 24 \\
\hline 2 & - & No & & & Neck & 228 & $\mathrm{R}$ & AWD & 266 \\
\hline 3 & + & No & & & Bone & 28 & $S+R$ & DOD & 48 \\
\hline 4 & - & No & & & Bone, choroid plexus, eye & 1 & $\mathrm{BSC}$ & DOD & 9 \\
\hline 5 & + & Yes & 46 & $\mathrm{~S}+\mathrm{R}$ & Bone & 46 & $\mathrm{C}+\mathrm{R}$ & DOD & 72 \\
\hline 6 & + & No & & & None & & & $\mathrm{DOC}$ & 80 \\
\hline 7 & + & Yes & 13 & $\mathrm{R}$ & None & & & DOD & 39 \\
\hline 8 & - & No & & & None & & & NED & 120 \\
\hline 9 & - & No & & & Lung, bone, lymph nodes & 7 & $\mathrm{BSC}$ & DOD & 10 \\
\hline 10 & - & No & & & Bone, lung, kidney, pancreas & 36 & $\mathrm{C}+\mathrm{R}$ & DOD & 97 \\
\hline 11 & - & Yes & 6 & $\mathrm{~S}+\mathrm{R}+\mathrm{C}$ & Lung, lymph nodes & 6 & $\mathrm{~S}+\mathrm{C}$ & DOD & 14 \\
\hline 12 & + & No & & & Bone & 18 & R & AWD & 72 \\
\hline 13 & + & Yes & 53 & BSC & Lung, bone, thyroid & 7 & $\mathrm{~S}+\mathrm{C}+\mathrm{RAl}+\mathrm{R}$ & DOD & 55 \\
\hline 14 & + & No & & & Bone & 6 & $\mathrm{BSC}$ & DOD & 20 \\
\hline 15 & + & Yes & 12 & S & None & & & AWD & 42 \\
\hline 16 & - & No & & & Bone & 18 & $S$ & AWD & 36 \\
\hline 17 & - & No & & & None & & & NED & 36 \\
\hline 18 & - & No & & & Lung & 21 & RAl & AWD & 24 \\
\hline
\end{tabular}

EBS, en bloc spondylectomy; C, chemotherapy; DOD, dead of disease; R, radiation therapy; AWD, alive with disease; S, surgery; DOC, dead from other causes; NED, no evidence of disease; BSC, best supportive care; RAl, radioactive iodine therapy. 

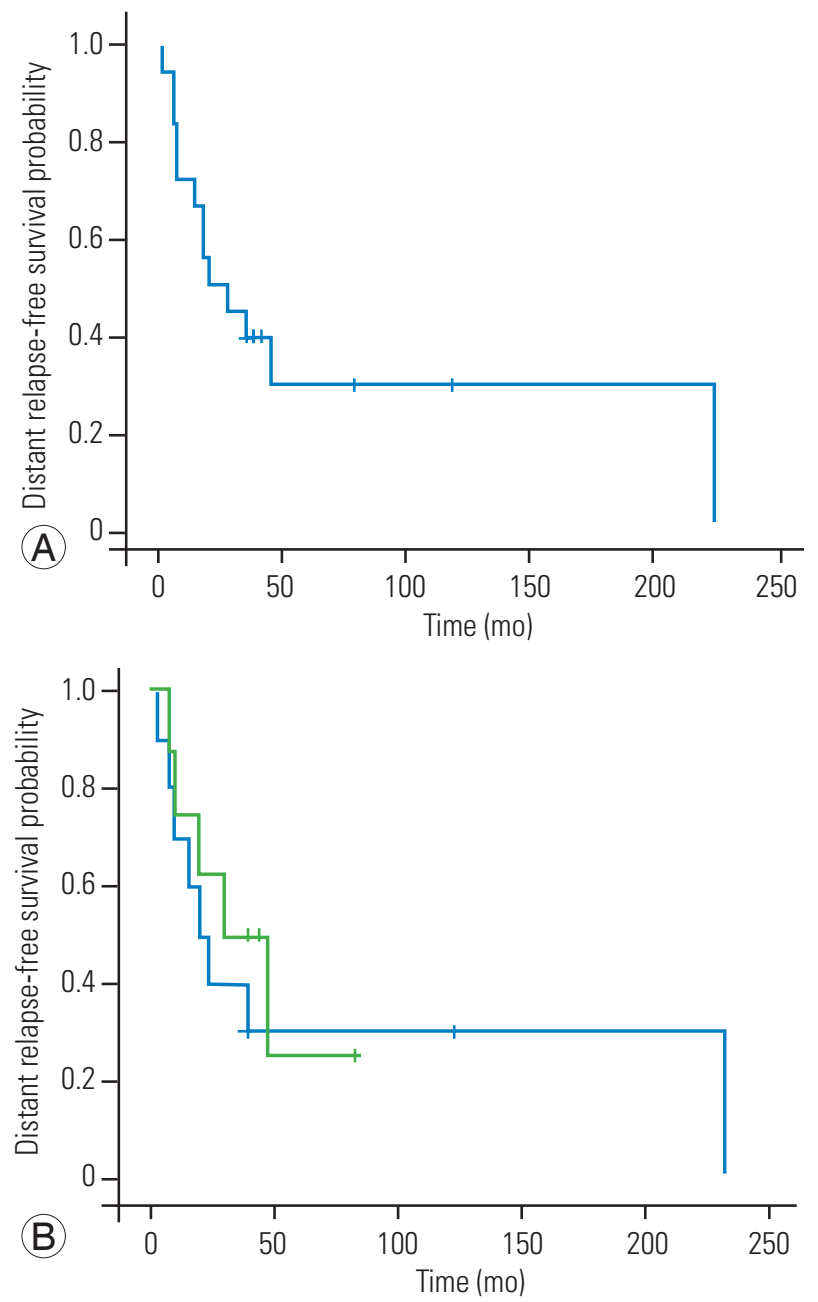

Fig. 1. Distant relapse-free survival curves. (A) Distant relapse-free survival in 18 patients who underwent en bloc spondylectomy for spinal metastases. (B) Comparison of the distant relapse-free survival curves for patients with (green line) and without (blue line) contaminated resected margins. No significant difference was found between groups ( $p=0.62)$.

tient with an accidental durotomy during EBS (case 15), the tumor recurred as an intradural-extramedullary tumor; this was removed completely during revision surgery and further treated by radiation therapy. Another patient (case 7) experienced tumor recurrence on the psoas major muscle and was treated with radiation therapy. Another tumor recurred paravertebral, at the retroperitoneal area, in one patient (case 13). This patient did not undergo further treatment given his poor general condition.

In the five patients without a new occurrence of distant relapse, the tumor origin was the kidney in three patients, liver in one patient, and thymoma in one patient. The distant relapse-free 1-year, 2-year, 3-year, and 5-year sur-

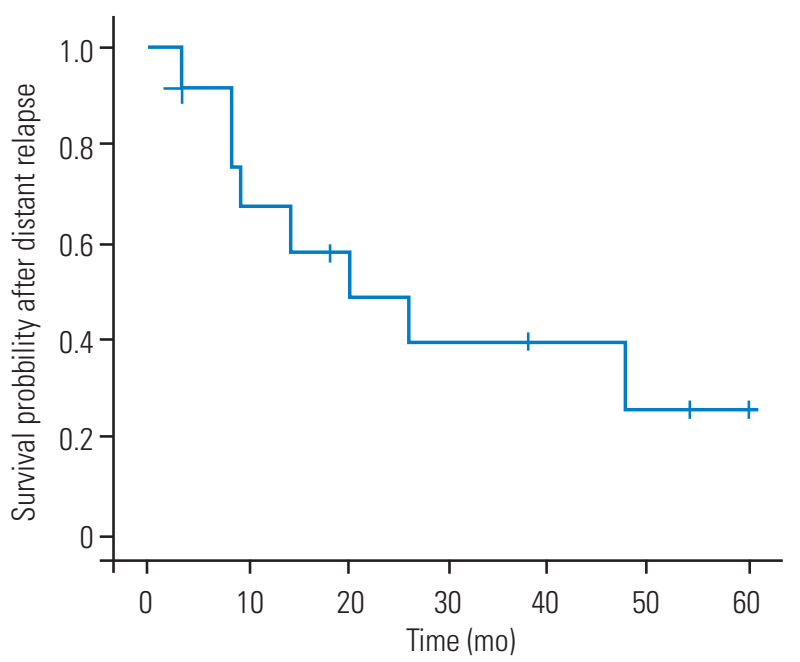

Fig. 2. Survival curve after distant relapse in 13 patients who experienced distant relapses after en bloc spondylectomy for spinal metastases.

vival rates after EBS were $72.2 \%, 50 \%, 38.9 \%$, and $29.2 \%$, respectively (Fig. 1). Overall, distant relapse was detected in 13 patients (72.2\%). The estimated median duration between EBS and distant relapse was 21 months (95\% confidence interval [CI], 0.21-41.79 months) (Fig. 1A). The incidence of distant relapse was $80 \%$ in patients with negative margins and $62.5 \%$ in patients with positive margins, with no significant differences between groups $(p=0.61)$. The differences in the surgical margin of the resected lesion did not affect the distant relapse-free survival period ( $p=0.62$ ) (Fig. 1B). Systemic adjuvant therapies, including chemotherapy and radioactive iodine therapy, also did not have a significant effect on the incidence of distant relapse, which occurred in $57.1 \%$ and $81.8 \%$ of patients who received and did not receive systemic adjuvant therapies, respectively $(p=0.33)$. Moreover, three of the four patients (75\%) with extraspinal metastatic lesions at the EBS site and 10 of the 14 patients (71.4\%) without extraspinal metastatic lesions at the EBS site experienced a new distant relapse occurrence after EBS. Still the incidence of distant relapses did not significantly differ between patients with and without extraspinal lesions at the EBS site ( $p>0.99)$. In the 13 patients with distant relapses, the 6-month, 1-year, 2-year, 3-year, and 5-year survival rates after distant relapse were $92.3 \%, 67.1 \%, 49.0 \%, 39.2 \%$, and $26.1 \%$, respectively (Fig. 2). The estimated median survival period after a distant relapse was 20 months (95\% CI, 0.71-39.29 months) (Fig. 2). The overall 2-year, 5-year, and 10-year survival rates after EBS were $72.2 \%, 48.8 \%$, and $27.1 \%$, re- 


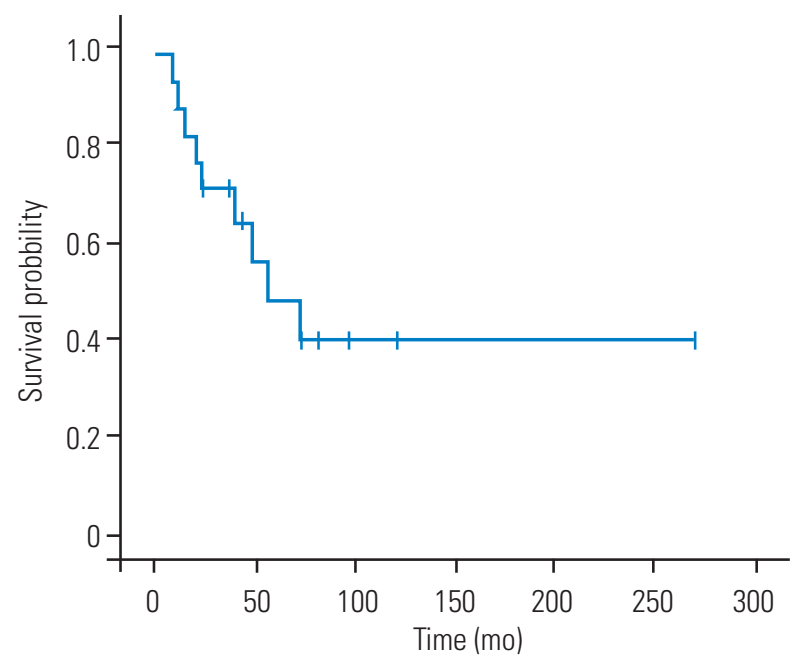

Fig. 3. Overall survival after en bloc spondylectomy for spinal metastases in 18 patients.

spectively, and the estimated median survival period was 55.2 months (95\% CI, 16.57-93.43 months) (Fig. 3).

Finally, because EBS was performed from 1991 to 2015, the year in which EBS was performed was evaluated in relation to oncological outcomes. There were no significant differences according to the year EBS was performed (median [interquartile range]) between the positive (2005 [2004-2012]) and negative (2008.5 [2002.5-2013]) resection margin groups $(p=0.96)$, between groups of patients with (2010 [2005-2012]) and without (2008 [2001-2013]) local recurrence $(p=0.73)$, and between groups of patients with (2008.5 [2001-2011.5]) and without (2007 [20052013]) distant relapse $(p=0.69)$.

\section{Discussion}

EBS remains one of the most challenging and technically demanding procedures for spine surgeons. In the present study, the median operative time was 12.8 hours, and the median blood loss was $2.4 \mathrm{~L}$, which are comparable to the values reported in previous studies [6,7]. In addition, the rate of perioperative complications was $66.7 \%$ in the present study, and the rate of perioperative mortality was $0 \%$. The higher rate of perioperative complications observed here, compared to previous reports $[7,16,17]$, might be due to the differences in the definition of complications. Indeed, despite the high incidence of perioperative complications, the results for survival are comparable to those of previous investigations $[6,7,18,19]$. Ultimately, lifespan extension was achieved, suggesting that the indicators used and perioperative care implemented during EBS for spinal metastases were appropriate.

Previous studies have reported that intralesional resections and EBS with contaminated margins will have a negative effect on local recurrence $[7,10,18,20]$. Certainly, the rate of local recurrence for EBS in the present study (27.8\%) was slightly higher than that of previous reports (5\%-20\%) $[6,7,10,18-20]$. This difference may be due to the high frequency (44.4\%) of EBS procedures with positive margins in the present study. Indeed, local recurrence tended to be observed more often in patients with positive margins than in patients with negative margins (50\% versus $10 \%$ ) in the present study.

In the present series, $72.2 \%$ of patients experienced newly formed distant metastases occurring after EBS. Cloyd et al. [7] conducted a systematic review and reported that the rate of any tumor recurrence (both local and distant relapses) after en bloc resection of metastatic spinal tumors was $37.7 \%$. The higher rate of distant relapses demonstrated in this study may be influenced by the longer follow-up period (median, 40.5 months versus 16 months). Indeed, the estimated duration between EBS and a distant relapse event had a median of 21 months, which is longer than the median follow-up period of the systematic review. Interestingly, the incidence of distant relapse was not associated with resection margin status or the presence of extraspinal metastatic lesions at the EBS site in the current study. In addition, obvious differences in distant relapse events were not observed among the tumors of different origins; however, the small sample size did not allow statistical analysis in this matter. Thus, EBS was not determined to completely prevent the occurrence of distant relapses in patients with spinal metastases. In the present study, $84.6 \%$ of patients with distant relapses received some treatment (radiotherapy, chemotherapy, or a combination of both) for distant metastases. Despite these treatments, more than half of the patients with distant relapses died within 2 years after relapse.

The limitations of the current study include its retrospective design, small sample size, and the inclusion of heterogeneous primary cancer sites. Because patients with spinal metastases requiring EBS are uncommon, future studies should involve prospective, multicenter collaborations. Moreover, although the era in which EBS was performed did not impact the surgical and oncological outcomes in this study, the 25-year span of the study was sufficiently long for cancer treatment to advance during 
the study period. Therefore, it should be noted that the outcomes in this study represent the minimum expected outcomes, given the present state of cancer treatment. In the future, the outcomes for EBS could be improved.

\section{Conclusions}

In conclusion, margin-free EBS is effective for the local control of spinal metastases. However, EBS by itself, even if margin-free, cannot completely prevent further dissemination. The present results regarding distant relapses after EBS will assist spinal surgeons in the clinical decisionmaking process and should be conveyed to patients and their families to help in treatment choices.

\section{Conflict of Interest}

No potential conflict of interest relevant to this article was reported.

\section{Acknowledgments}

The authors wish to thank the physicians in the Niigata Spine Group who contributed to the treatment of this series of patients.

\section{Author Contributions}

Masayuki Ohashi wrote and prepared the manuscript. Masayuki Ohashi, Kei Watanabe, Toru Hirano, Kazuhiro Hasegawa, Keiichi Katsumi, Hirokazu Shoji, and Tatsuki Mizouchi contributed to the conception and design of this study, data acquisition, and analysis and interpretation of the data. Takao Homma and Naoto Endo contributed to the study design, analysis and interpretation of data, and supervision. All authors have read, reviewed, and approved the article.

\section{References}

1. Chaichana KL, Woodworth GF, Sciubba DM, et al. Predictors of ambulatory function after decompressive surgery for metastatic epidural spinal cord compression. Neurosurgery 2008;62:683-92.

2. Kim CH, Chung CK, Jahng TA, Kim HJ. Resumption of ambulatory status after surgery for nonambulatory patients with epidural spinal metastasis. Spine J
2011;11:1015-23.

3. Kim CH, Chung CK, Jahng TA, Kim HJ. Surgical outcome of spinal hepatocellular carcinoma metastases. Neurosurgery 2011;68:888-96.

4. Tomita K, Kawahara N, Baba H, Tsuchiya H, Nagata S, Toribatake Y. Total en bloc spondylectomy for solitary spinal metastases. Int Orthop 1994;18:291-8.

5. Hasegawa K, Homma T, Hirano T, et al. Margin-free spondylectomy for extended malignant spine tumors: surgical technique and outcome of 13 cases. Spine (Phila Pa 1976) 2007;32:142-8.

6. Tomita K, Kawahara N, Murakami H, Demura S. Total en bloc spondylectomy for spinal tumors: improvement of the technique and its associated basic background. J Orthop Sci 2006;11:3-12.

7. Cloyd JM, Acosta FL Jr, Polley MY, Ames CP. En bloc resection for primary and metastatic tumors of the spine: a systematic review of the literature. Neurosurgery 2010;67:435-44.

8. Kato S, Murakami H, Demura S, et al. More than 10year follow-up after total en bloc spondylectomy for spinal tumors. Ann Surg Oncol 2014;21:1330-6.

9. Matsumoto M, Tsuji T, Iwanami A, et al. Total en bloc spondylectomy for spinal metastasis of differentiated thyroid cancers: a long-term follow-up. J Spinal Disord Tech 2013;26:E137-42.

10. Demura S, Kawahara N, Murakami H, et al. Total en bloc spondylectomy for spinal metastases in thyroid carcinoma. J Neurosurg Spine 2011;14:172-6.

11. Kato S, Murakami H, Demura S, et al. The impact of complete surgical resection of spinal metastases on the survival of patients with thyroid cancer. Cancer Med 2016;5:2343-9.

12. Tomita K, Kawahara N, Kobayashi T, Yoshida A, Murakami H, Akamaru T. Surgical strategy for spinal metastases. Spine (Phila Pa 1976) 2001;26:298-306.

13. Boriani S, De Iure F, Bandiera S, et al. Chondrosarcoma of the mobile spine: report on 22 cases. Spine (Phila Pa 1976) 2000;25:804-12.

14. Frankel HL, Hancock DO, Hyslop G, et al. The value of postural reduction in the initial management of closed injuries of the spine with paraplegia and tetraplegia: I. Paraplegia 1969;7:179-92.

15. Tokuhashi Y, Matsuzaki H, Oda H, Oshima M, Ryu J. A revised scoring system for preoperative evaluation of metastatic spine tumor prognosis. Spine (Phila Pa 1976) 2005;30:2186-91. 
16. Yamazaki T, McLoughlin GS, Patel S, Rhines LD, Fourney DR. Feasibility and safety of en bloc resection for primary spine tumors: a systematic review by the Spine Oncology Study Group. Spine (Phila Pa 1976) 2009;34(22 Suppl):S31-8.

17. Yokogawa N, Murakami H, Demura S, et al. Perioperative complications of total en bloc spondylectomy: adverse effects of preoperative irradiation. PLoS One 2014;9:e98797.

18. Li H, Gasbarrini A, Cappuccio M, et al. Outcome of excisional surgeries for the patients with spinal metastases. Eur Spine J 2009;18:1423-30.
19. Lee BH, Park JO, Kim HS, Park YC, Lee HM, Moon $\mathrm{SH}$. Perioperative complication and surgical outcome in patients with spine metastases: retrospective 200case series in a single institute. Clin Neurol Neurosurg 2014;122:80-6.

20. Sundaresan N, Rothman A, Manhart K, Kelliher K. Surgery for solitary metastases of the spine: rationale and results of treatment. Spine (Phila Pa 1976) 2002;27:1802-6. 